\title{
TLR7 Ligation Inhibits TLR8 Responsiveness in IL-27-Primed Human THP-1 Monocytes and Macrophages
}

\author{
Natalya Odoardi Olena Kourko Carlene Petes Sameh Basta Katrina Gee \\ Department of Biomedical and Molecular Sciences, Queen's University, Kingston, ON, Canada
}

\section{Keywords}

Interleukin-27 - Toll-like receptor 7 - Toll-like receptor 8 .

Toll-like receptor · Interferon · Monocytes · Macrophages .

Inflammation

\begin{abstract}
Regulation of proinflammatory cytokine expression is critical in the face of single-stranded RNA (ssRNA) virus infections. Many viruses, including coronavirus and influenza virus, wreak havoc on the control of cytokine expression, leading to the formation of detrimental cytokine storms. Understanding the regulation and interplay between inflammatory cytokines is critical to the identification of targets involved in controlling the induction of cytokine expression. In this study, we focused on how the antiviral cytokine interleukin-27 (IL-27) regulates signal transduction downstream of Toll-like receptor 7 (TLR7) and TLR8 ligation, which recognize endosomal single-stranded RNA. Given that IL-27 alters bacterial-sensing TLR expression on myeloid cells and can inhibit replication of single-stranded RNA viruses, we investigated whether IL-27 affects expression and function of TLR7 and TLR8. Analysis of IL-27-treated THP-1 monocytic cells and THP-1-derived macrophages revealed changes in mRNA and protein expression of TLR7 and TLR8. Although treat-
\end{abstract}

karger@karger.com www.karger.com/jin

Karger:

bOPEN ACCESS
(C) 2021 The Author(s).

Published by S. Karger AG, Basel

This is an Open Access article licensed under the Creative Commons Attribution-NonCommercial-4.0 International License (CC BY-NC) (http://www.karger.com/Services/OpenAccessLicense), applicable to the online version of the article only. Usage and distribution for commercial purposes requires written permission. ment with IL-27 enhanced TLR7 expression, only TLR8-mediated cytokine secretion was amplified. Furthermore, we demonstrated that imiquimod, a TLR7 agonist, inhibited cytokine and chemokine production induced by a TLR8 agonist, TL8-506. Delineating the immunomodulatory role of IL27 on TLR7 and TLR8 responses provides insight into how myeloid cell TLR-mediated responses are regulated during virus infection.

(C) 2021 The Author(s)

Published by S. Karger AG, Basel

\section{Introduction}

Innate immune cells, such as monocytes and macrophages, express Toll-like receptors (TLRs), which recognize highly conserved pathogen-associated molecular patterns (PAMPs) such as viral and bacterial products. TLRs localized within the endosome are involved in the response to viral infection; these include TLR3, 7, 8, and 9 [1]. Specifically, TLR7 and TLR8 recognize singlestranded RNA (ssRNA), a common feature of viral genomes such as coronavirus (i.e., SARS-CoV-2), influenza A virus (IAV), human immunodeficiency virus (HIV), and hepatitis $\mathrm{C}$ virus (HCV), as well as small synthetic ssRNA analogs like resiquimod (R848) [2-4]. TLR7 and 
TLR8 signal through the myeloid differentiation primary response gene 88 (MyD88) signaling cascade, resulting in the activation of mitogen-activated protein kinase (MAPK) signaling molecules, such as p38, extracellular signal-regulated kinases (ERK) 1/2, c-Jun N-terminal kinases (JNK), and nuclear translocation of transcription factors such as nuclear factor (NF)- $\mathrm{kB}$ and activator protein (AP)-1 [2, 5-8]. Subsequently, proinflammatory cytokines, chemokines, and type I interferons (IFNs) are produced $[7,9-11]$, resulting in the induction of a proinflammatory environment, recruitment of circulating immune cells, and activation of adaptive immunity.

Discovered by Pflanz et al. [12] interleukin (IL)-27 is a heterodimeric cytokine shown to have various immunomodulatory properties on innate immune cells, along with antiviral properties against HIV-1, HCV, and IAV [13-19]. Furthermore, viral infection induces expression of IL-27; for example, IAV infection elicits IL-27 expression in human monocytes, lymphocytes, and peripheral blood mononuclear cells [19]. These findings suggest an important role for IL-27 in the antiviral response against ssRNA viruses. Given that IL-27 enhances the signaling capacity and cytokine production in response to TLR2, TLR4, and TLR5 activation in human monocytes and macrophages (including primary human cells and human cell lines) [20-24], we hypothesized that IL-27 may exert similar regulatory effects on TLR7 and TLR8 as a mechanism for its antiviral effects. Therefore, we examined how IL-27 priming of cells changed TLR7 and/or TLR8-mediated cytokine induction to predict how virusinduced IL-27 expression might influence the innate immune response in uninfected bystander cells.

In this study, we examined the effects of IL-27 treatment on TLR7 and TLR8 expression and function using the human THP-1 cell line to model monocyte and macrophage responses. Cytokine and chemokine induction in response to a panel of specific TLR7, TLR8, or dual TLR7/8 agonists were used to quantify TLR responsiveness in terms of MAPK, NF- $\kappa \mathrm{B}$, and AP- 1 activation as well as inflammatory cytokine and chemokine induction. We show that IL-27 stimulation resulted in increased phosphorylation of $\mathrm{p} 38$ and ERK1/2 MAPK as well as increased activation of NF- $\kappa \mathrm{B} / \mathrm{AP}-1$. Further, our data demonstrate that IL-27 enhanced the expression of TLR7, but not of TLR8; however, IL-27 treatment enhanced both TLR8-specific and TLR7/8 dual ligand-induced cytokine and chemokine expression. Interestingly, the coaddition of TLR7 ligand with TLR8 ligand resulted in the inhibition of TLR8-induced proinflammatory cytokine expression. Identifying IL-27-mediated mechanisms to modulate TLR7/8 responses on myeloid cells will provide insight into the antiviral functions of IL-27 and its role in the innate immune response.

\section{Methods}

Cell Lines, Cell Culture, and Reagents

THP-1 cells, purchased from the American Type Culture Collection (ATCC, Manassas, VA, USA), were cultured in RPMI 1640 medium (Gibco by Life Technologies, Carlsbad, CA, USA) supplemented with $10 \%$ fetal bovine serum (FBS) (Hyclone, Logan, UT, USA). THP-1 XBlue cells were purchased from InvivoGen (San Diego, CA, USA) and cultured in RPMI 1640 medium in the presence of Zeocin $(200 \mu \mathrm{g} / \mathrm{mL}$; InvivoGen $)$. THP-1 and THP-1 XBlue cells were differentiated into macrophage-like cells using RPMI 1640 medium supplemented with 10\% FBS and phorbol 12-myristate 13 -acetate (PMA, 10 ng/mL; BioShop Canada Inc., Burlington, ON, USA) for $48 \mathrm{~h}$, followed by RPMI 1640 medium $+10 \%$ FBS for a subsequent 48-h incubation. Recombinant human IL-27 was purchased from R\&D Systems (Minneapolis, MN, USA) and was used at a dose of $50 \mathrm{ng} / \mathrm{mL}$ for $16 \mathrm{~h}$, as described in previous studies [22, 25]. Synthetic TLR7 and TLR8 agonist analogs imiquimod (IMQ), R848, CL075, and TL8-506 (TL8) were purchased from InvivoGen. Concentrations of agonists were determined following the manufacturer's recommendations and dose response stimulations in THP-1 and PMA-THP-1 cells.

\section{Flow Cytometry}

For intracellular staining, cells were fixed with $4 \%$ paraformaldehyde then permeabilized with $0.2 \%$ saponin. Cells were stained with anti-human TLR7-PE-conjugated murine monoclonal antibody (eBioscience/Thermo Fisher Scientific, Waltham, MA, USA) or anti-human TLR8-APC750-conjugated murine monoclonal antibody (eBioscience) for $1 \mathrm{~h}$ at room temperature. Data were acquired with the CytoFLEX flow cytometer (Beckman Coulter, Pasadena, CA, USA) and analyzed using FlowJo software, version X 10.5.0 (Ashland, OR, USA).

RNA Isolation and Quantitative Polymerase Chain Reaction

The GENEzol TriRNA pure kit (Geneaid, New Taipei City, Taiwan) was used to extract total RNA from cell pellets and RNA was subjected to DNase treatment according to the manufacturer's protocol. RNA was reverse transcribed using iScript ${ }^{\mathrm{TM}}$ Reverse Transcription Supermix (Bio-Rad Laboratories, Hercules, CA, USA). In brief, quantitative real-time PCR (qPCR) reactions were performed using the SsoAdvanced Universal SYBR Green Supermix and PrimePCR human TLR7 and TLR8 primers (Bio-Rad Laboratories). qPCR data were acquired using the CFX96 Touch $^{\mathrm{TM}}$ Real-Time PCR Detection System. All qPCR analyses were performed using the CFX Maestro Software (Bio-Rad Laboratories) which utilizes the $\Delta \mathrm{C}_{\mathrm{T}}$ method. Target gene expression was normalized to the reference gene, GAPDH. Fold change was calculated between the normalized relative expression $\left(\Delta C_{T}\right)$ of the control and treatment groups.

SEAP QUANTI-Blue ${ }^{T M}$ Assay

NF- $\kappa$ B/AP-1-inducible secreted embryonic alkaline phosphatase (SEAP) was measured using THP-1 XBlue cells plated at $2 \times$ 
$10^{5}$ cells $/ \mathrm{mL}$ in $180 \mu \mathrm{L}$ per well. Reagents (medium, IL-27, IMQ, TL8, R848, and CL075) were added to a total volume of $20 \mu \mathrm{L}$ per well and incubated for $24 \mathrm{~h}$ at $37^{\circ} \mathrm{C}$ with $5 \% \mathrm{CO}_{2}$. SEAP production was quantified by combining $20 \mu \mathrm{L}$ of cell-free supernatant with $180 \mu \mathrm{L}$ QUANTI-Blue ${ }^{\mathrm{TM}}$ buffer (InvivoGen) and incubated at $37^{\circ} \mathrm{C}$ for $3 \mathrm{~h}$. Optical density was measured at $650 \mathrm{~nm}$ on a Varioskan spectrophotometer (Thermo Fisher Scientific).

\section{Western Blotting}

Cell pellets were lysed with lysis buffer (1 M HEPES, 0.5 M NaF, $0.5 \mathrm{M}$ EGTA, $2.5 \mathrm{M} \mathrm{NaCl}, 1 \mathrm{M} \mathrm{MgCl}_{2}, 10 \%$ glycerol, and $1 \%$ Triton $\mathrm{X}-100)$ containing HALT protease and phosphatase inhibitor (Thermo Fisher Scientific). Protein concentrations were measured with a Bradford assay (Sigma-Aldrich, St. Louis, MO, USA). Samples $(10 \mu$ g protein) were separated on a $10 \%$ polyacrylamide SDSPAGE then transferred onto polyvinylidene difluoride membranes (Bio-Rad Laboratories). Blocking was performed using 2.5\% bovine serum albumin (BioShop Canada Inc.) in Tris-buffer saline (TBS) with $0.1 \%$ Tween (BioShop Canada Inc.) (TBST) for $2 \mathrm{~h}$. Membranes were probed with anti-phospho- and anti-pan-antibodies for each of NF- $\mathrm{B}$ p 65, p38, and MAPK (ERK1/2) p44/42 (Cell Signaling Technology, Danvers, MA, USA) at either 1:1,000 or $1: 10,000$ dilution in $2.5 \%$ bovine serum albumin in TBST. Mouse anti-rabbit IgG-HRP or a goat anti-mouse IgG-HRP secondary antibody was used at a dilution of 1:10,000 (Santa Cruz Biotechnologies, Inc., Dallas, TX, USA). Immunoblots were visualized using Clarity ECL (Bio-Rad Laboratories) on an Alpha Innotech HD2 imager (Thermo Fisher Scientific). Using the HD2 Imaging software, the intensity of phospho-specific bands was normalized to pan-bands and then fold change was calculated to medium cultured cells (lane 1) for each cell type and antibody pairs.

\section{Enzyme-Linked Immunosorbent Assay}

Cytokine expression was quantified in cell-free supernatants according to manufacturer's instructions for human TNF- $\alpha$, IL-6 (Thermo Fisher Scientific Invitrogen eBioscience, Carlsbad, CA, USA), IL-8, and CCL5 (RANTES) (BioLegend, San Diego, CA, USA). Absorbance was measured with the ELx800 Microplate Reader (BioTek, Winooski, VT, USA) at $450 \mathrm{~nm}$. Data are representative of the average \pm SD from at least 5 independent experiments.

\section{Statistical Analysis}

Statistical significance was determined using either unpaired, 2 -tailed, nonparametric $t$ tests or with a one-way ANOVA with multiple comparisons (unpaired, nonparametric) between specified conditions. ${ }^{*} p \leq 0.05 ;{ }^{* *} p \leq 0.01 ;{ }^{* * *} p \leq 0.001 ;{ }^{* * * *} p \leq 0.0001$.

\section{Results}

TLR7- and TLR8-Mediated p38, ERK1/2, and NF$\mathrm{Kb}$ Activation Is Differentially Modulated in IL-27-

Pretreated THP-1 and PMA-THP-1 Cells

IL-27 modulates various signaling pathways downstream of TLR4 activation [22, 24, 26, 27]; though the influence of IL-27 on the signaling of TLRs responsible for recognition of ssRNA has not been investigated in my- eloid cells. Since IL-27 induces antiviral immune responses resulting in the inhibition of ssRNA virus replication like HIV [17, 28], influenza [19], and hepatitis C [16], we reasoned that IL-27 may affect the function of endosomal TLR7 and TLR8. We used the human monocytic cell line THP-1 as our model system because they can be differentiated with PMA treatment to model the macrophage response (PMA-THP-1) [29]. Compared to primary monocytes and macrophages, THP- 1 and PMA-THP-1 cells can exhibit similar outcomes with respect to TLR and IL-27 responsiveness [20-23, 25, 26].

To determine if IL-27 impacts TLR7 and TLR8 signaling, we treated THP-1 and PMA-THP-1 cells with IL-27 for $16 \mathrm{~h}$ prior to stimulation with TLR7 (IMQ) and TLR8 (TL8-506: TL8) agonists or dual TLR7/8 agonists (R848 or CL075). The $16 \mathrm{~h}$ time point for IL-27-priming was previously found to influence TLR4 expression and responsiveness [20]. We used IL-27 at a dose of $50 \mathrm{ng} / \mathrm{mL}$, within the range we have used previously [25] and in line with others who have demonstrated the antiviral effects of IL-27 [16, 17, 19, 28].

Key members of the MAPK signaling pathway were examined: phosphorylation of $\mathrm{p} 38$ and ERK1/2, as well as activation of the transcription factors NF- $\mathrm{BB}$ and AP-1. For measurement of p38 and ERK1/2 phosphorylation, THP-1 or PMA-THP-1 cells were treated with IL-27 (50 $\mathrm{ng} / \mathrm{mL}$ ) for $16 \mathrm{~h}$, washed with culture medium, then exposed to IMQ ( $5 \mu \mathrm{g} / \mathrm{mL})$, TL8 (500 ng/mL), R848 (5 $\mu \mathrm{g} /$ $\mathrm{mL})$, or CL075 $(2.5 \mu \mathrm{g} / \mathrm{mL})$ for $15 \mathrm{~min}$. In THP-1 cells, IL27 treatment induced a modest, but significant, increase in phosphorylation of p38 and ERK1/2 in control cells (Fig. 1a: left panel, lanes 1, 2; Fig. 1b: left panels). Treatment with specific TLR7 and/or TLR8 agonists alone resulted in the phosphorylation of $\mathrm{p} 38$, and ERK1/2 comparable to medium cultured cells (Fig. 1a; lanes 3, 5, 7, 9). Similarly, in PMA-THP-1 cells, IL-27 treatment resulted in significantly enhanced p38 and ERK1/2 phosphorylation compared to medium cultured cells (Fig. 1a: right panel, lanes 1, 2; Fig 1b: right panels). As in THP-1 cells, stimulation of PMA-THP-1 cells with TLR7 and TLR8 agonists resulted in enhanced $\mathrm{p} 38$ and ERK1/2 phosphorylation compared to medium (Fig. 1b; lanes 3, 5, 7, 9). Pretreatment with IL27 followed by TLR agonists did not significantly impact p-p38 or p-ERK levels in response to TLR7 or TLR8 agonists in either cell type. Overall, in THP-1 and PMA-THP-1 cells, treatment with IL-27 enhanced phosphorylation of p38 and ERK1/2, which was maintained post-TLR ligation.

To further investigate the effect of IL-27 on TLR7- and TLR8-induced signaling, TLR7- and TLR8-induced NF$\kappa \mathrm{B} / \mathrm{AP}-1$ activity was examined, as these transcription fac- 
tors are critical regulators of inflammatory cytokine expression. The THP-1 XBlue cell line contains an NF- $\kappa \mathrm{B} /$ AP-1-inducible SEAP reporter gene which was used to examine relative NF- $\mathrm{KB} / \mathrm{AP}-1$ activity, as previously described $[22,30]$. THP-1 XBlue or PMA-THP-1 XBlue cells were pretreated with IL-27 for $16 \mathrm{~h}$, then washed and stimulated with TLR7 or TLR8 agonists for $24 \mathrm{~h}$, to allow for SEAP production. Relative NF- $\mathrm{B} / \mathrm{AP}-1$-induced SEAP activity was quantified in supernatants. Significantly greater NF- $\kappa \mathrm{B} / \mathrm{AP}-1$ activity was observed in THP-1 XBlue cells following IL-27 treatment compared to medium controls (Fig. 1c), as previously reported [26]. IL-27 pretreatment also significantly increased NF- $\kappa \mathrm{B} / \mathrm{AP}-1 \mathrm{ac}-$ tivity when THP-1 XBlue cells were stimulated with TLR7 agonist IMQ, TLR8 agonist TL8, and TLR7/8 dual agonists R848 and CL075. Notably, IL-27 enhanced TLR8induced signaling more than TLR7 signaling in THP-1 XBlue cells (Fig. 1c, left). In PMA-THP-1 XBlue cells, however, IL-27 did not significantly alter NF- $\mathrm{kB} / \mathrm{AP}-1 \mathrm{ac}-$ tivity following stimulation with any of the TLR7 or TLR8 agonists (Fig. 1c, right). TLR7/8 dual agonists R848 and CL075 induced significantly more NF- $\mathrm{\kappa B} / \mathrm{AP}-1$ activity than the TLR7- or TLR8-specific agonists in both untreated and IL-27-treated PMA-THP-1 XBlue cells compared to control medium and IL-27-treated cells (Fig. 1c, right). These results suggest that THP-1 cells are more responsive to the TLR8 agonist (TL8) and the dual agonists (R848 and CL075) after IL-27 treatment, while PMA-THP-1 cells are more responsive to only the dual agonists (R848 and CL075), irrespective of IL-27 addition.

\section{IL-27 Pretreatment of Monocytes and Macrophages}

Results in Enhanced Proinflammatory Cytokine and

Chemokine Production

Our group and others have previously demonstrated that IL-27 induces the production of proinflammatory

Fig. 1. TLR7- and TLR8-mediated p38, ERK1/2, and NF- $\kappa$ B activation is differentially modulated in IL-27-pretreated THP-1 and PMA-THP-1 cells. a THP-1 cells and PMA-THP-1 cells were treated with or without IL-27 (50 ng/mL) for $16 \mathrm{~h}$, washed, then stimulated with agonists: IMQ (5 $\mu \mathrm{g} / \mathrm{mL}), \mathrm{TL} 8-506$ (TL8) $(500 \mathrm{ng} /$ $\mathrm{mL}), \mathrm{R} 848(5 \mu \mathrm{g} / \mathrm{mL})$, or CL075 $(2.5 \mu \mathrm{g} / \mathrm{mL})$ for $15 \mathrm{~min}$. Lysates were run on SDS-PAGE gels for immunoblot analysis and probed for phosphorylated proteins: p-p38, p-p42/44 ERK1/2. Membranes were then stripped and reprobed for corresponding pan protein counterparts as a loading control. b Fold change was calculated by normalizing respective phosphorylated lanes to pan controls and then calculating fold change over medium control. Images are representative of at least 2 independent experiments. c THP-1 XBlue cells and PMA-THP-1 XBlue cells were treated cytokines in primary human monocytes and macrophages as well as in THP- 1 cells and PMA-THP1 cells [20, 22-26]. Furthermore, IL-27 can induce type I IFN production expression in human macrophages cells [28]. Thus, we tested whether IL-27 modulated type I IFN expression. THP-1 and PMA-THP-1 cells were pretreated with IL-27 for $16 \mathrm{~h}$, washed with medium, and then stimulated with IMQ, TL8, R848, or CL075 for $24 \mathrm{~h}$ for enzyme-linked immunosorbent assay analysis of IFN- $\beta$ production. Interestingly we did not detect any secreted IFN- $\alpha$ nor IFN- $\beta$ under any condition (data not shown), indicating that the type I IFN response is not induced under our conditions.

Based on the differential signaling that we observed in Figure 1, we next decided to examine induction of inflammatory cytokines and chemokines that rely on the activation of NF- $\kappa \mathrm{B} / \mathrm{AP}-1$ and recruit immune cells to sites of viral infection [31]: IL- 6 and TNF- $\alpha$ and IL- 8 and RANTES (CCL5). To assess how IL-27 impacts TLR7- or TLR8-induced proinflammatory cytokine/chemokine production, THP-1 and PMA-THP-1 cells were pretreated with IL-27 for $16 \mathrm{~h}$, washed with medium, then stimulated with IMQ, TL8, R848, or CL075 for $24 \mathrm{~h}$. Cell-free supernatants were used to measure TNF- $\alpha$, IL-6, IL-8, and RANTES production by enzyme-linked immunosorbent assay.

In THP- 1 cells, treatment with each TLR agonist alone resulted in low levels of TNF- $\alpha$ secretion compared to medium control cells (Fig. 2a; black bars). In response to R848 and CL075 only, low levels of IL-6 were induced (Fig. 2c; black bars). Treatment of THP-1 cells with IL-27 alone resulted in upregulated TNF- $\alpha$ and IL- 6 production (Fig. 2a, c; control bars). Pretreatment of THP-1 cells with IL-27 followed by stimulation with TLR agonists resulted in significantly enhanced TNF- $\alpha$ and IL- 6 expression compared to levels of cytokine expressed in response to

with IL-27 (50 ng/mL) overnight, then stimulated with IMQ (5 $\mu \mathrm{g} /$ $\mathrm{mL})$, TL8 (500 $\mathrm{ng} / \mathrm{mL}), \mathrm{R} 848(5 \mu \mathrm{g} / \mathrm{mL})$, or CL075 $(2.5 \mu \mathrm{g} / \mathrm{mL})$ for $24 \mathrm{~h}$ to allow for NF- $\kappa \mathrm{B} / \mathrm{AP}-1$-induced SEAP production and secretion. SEAP production was quantified using a colorimetric QUANTI-Blue ${ }^{\mathrm{TM}}$ assay measured at $650 \mathrm{~nm}$. Data represent the mean and standard deviation of 3 independent experiments. An ordinary one-way ANOVA with multiple comparisons was used to determine statistical significance between pairs as indicated. ${ }^{*} p$ $\leq 0.05 ;{ }^{* *} p \leq 0.01 ;{ }^{* * *} p \leq 0.001 ;{ }^{* * * *} p \leq 0.0001$. IMQ, imiquimod; R848, resiquimod; SEAP, secreted embryonic alkaline phosphatase; TLR7, Toll-like receptor 7; TLR8, Toll-like receptor 8; IL-27, interleukin-27. ERK1/2, extracellular signal-regulated kinases 1/2; PMA, phorbol 12-myristate 13-acetate.

(For figure see next page.)
Odoardi/Kourko/Petes/Basta/Gee 


\section{THP-1 cells}
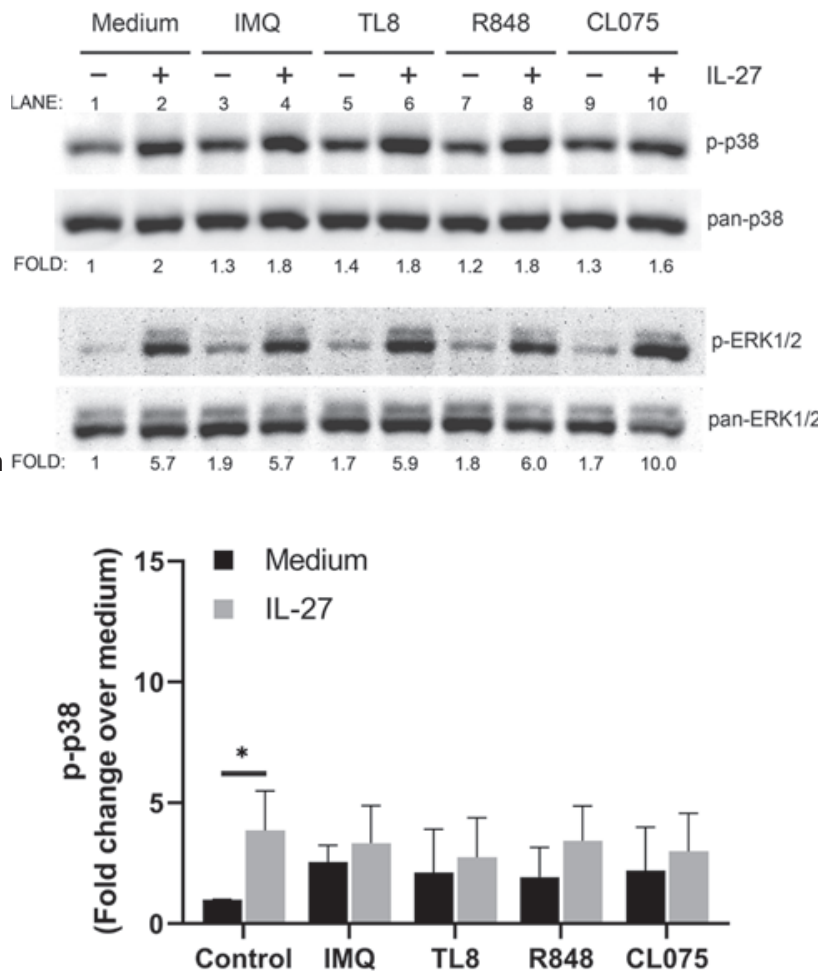

b
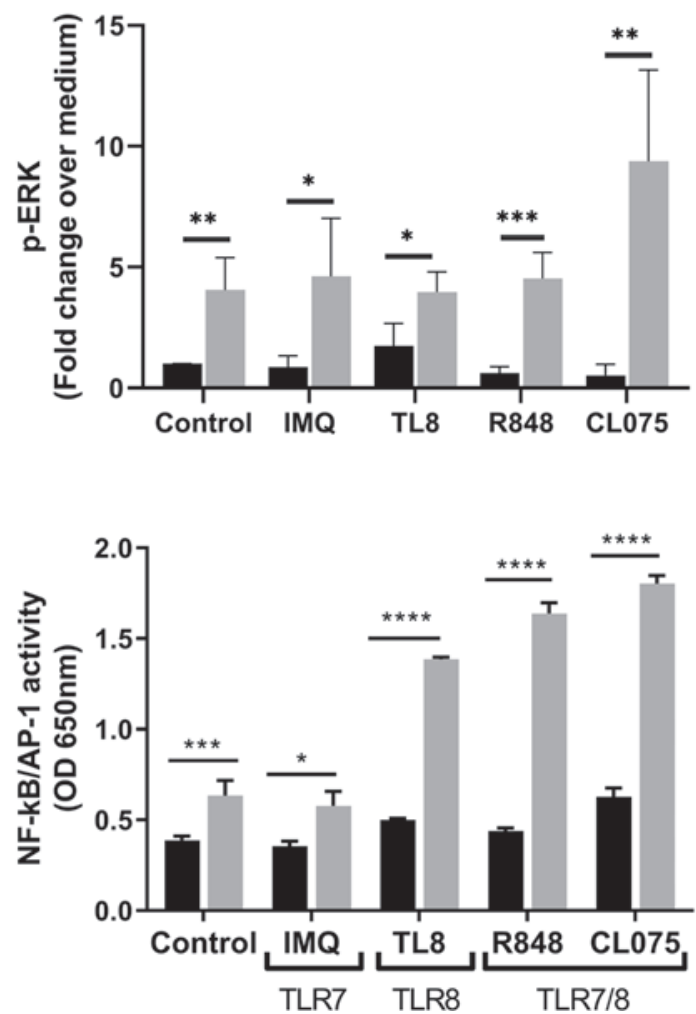

\section{PMA THP-1 cells}
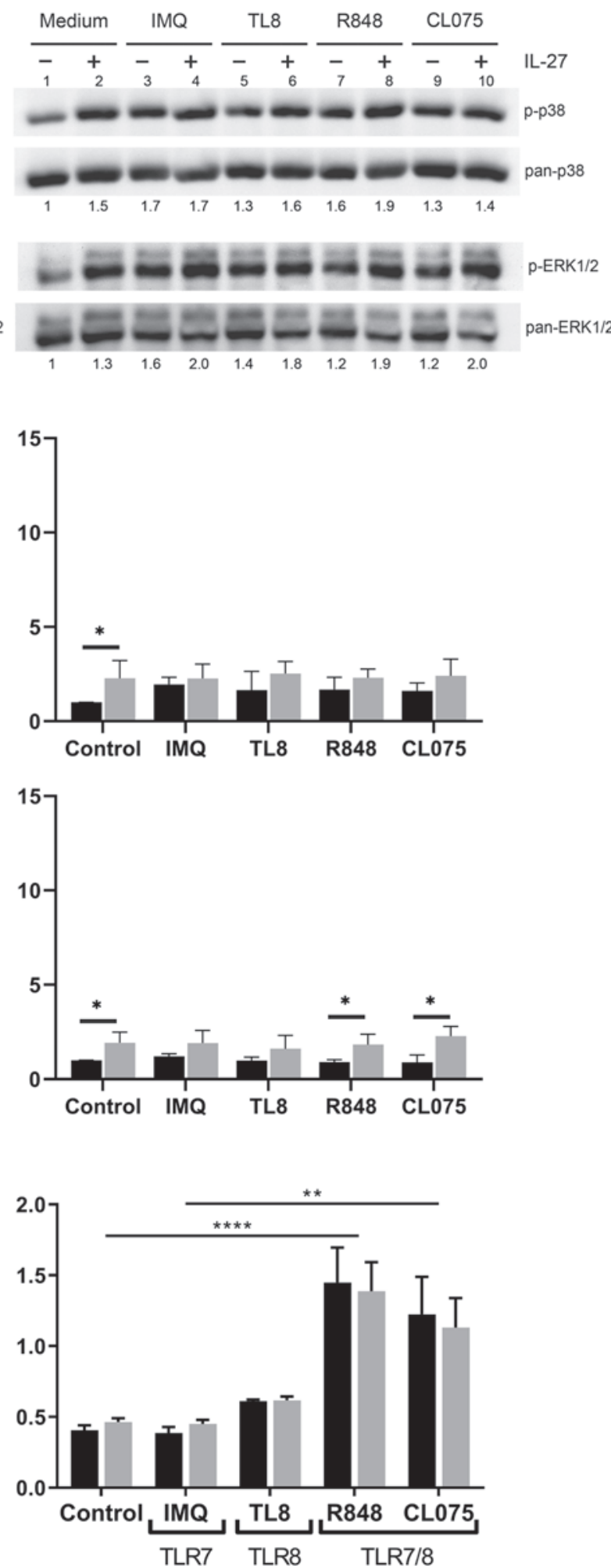
TLR agonists in the absence of IL-27 (Fig. 2a, c; gray bars compared to black bars).

In PMA-THP-1 cells, stimulation with TL8, R848, and CL075 resulted in enhanced TNF- $\alpha$ and IL- 6 expression, which was greater than that observed in THP-1 cells (Fig. 2b, $\mathrm{d}$; black bars). In cells pretreated with IL-27, upregulation of TNF- $\alpha$ and IL- 6 was observed in comparison to cells cultured in medium alone (Fig. 2b, d; control). Similar to THP1 cells, pretreatment of PMA-THP-1 cells with IL-27 followed by stimulation with TL8, R848, and CL075 further enhanced cytokine expression compared to cells treated with agonist alone (Fig. 2b, d; gray bars compared to black bars). Stimulation with IMQ resulted in low levels of IL-6 production from PMA-THP-1 cells pretreated with IL-27 (Fig. 2d), however, levels of TNF- $\alpha$ remained undetectable.

With respect to chemokine induction, in both THP-1 and PMA-THP-1 cells, each TLR agonist induced greater production of IL-8 and RANTES in comparison to medium cultured cells, with the exception of IMQ in PMATHP-1 cells (Fig. 2e-h; black bars). Stimulation of THP-1 cells with IL-27 alone increased IL-8 and RANTES expression compared to medium cultured cells, but this was not observed in PMA-THP-1 cells (Fig. 2e-h; gray bars). However, pretreatment with IL-27 followed by stimulation with TL8, R848, or CL075 significantly enhanced production of IL-8 and RANTES from both cell types (Fig. 2e-h; comparing gray bars to black bars). Interestingly, the addition of IMQ to IL-27-treated cells did not significantly alter chemokine responses in THP-1 or PMA-THP-1 cells compared to cells treated with IL-27 alone (Fig. 2e-h; comparing gray bars between control and IMQ). Taken together, IL-27 pretreatment of THP-1 monocytes and PMA-THP-1 macrophages significantly increased cytokine and chemokine production in response to TLR8 and TLR7/8 agonists, and to a lesser extent in response to TLR7 ligation by IMQ.

\section{Activation of TLR7 following IL-27 Pretreatment}

Results in Reduced TLR8-Induced Cytokine Production

We observed that IMQ stimulation of IL-27-treated THP-1 and PMA-THP-1 cells resulted in lower levels of
TNF- $\alpha$ and IL- 6 compared to cells treated with IL-27 alone (Fig. 2a-d). The IMQ-mediated effect is specific to the cytokines, as expression of the 2 chemokines, IL- 8 and RANTES, were not significantly affected by IMQ in IL-27 pretreated cells. In order to investigate the possible interplay between TLR7 and TLR8, we treated cells with either TL8 alone, IMQ alone, or a combination of TL8 and increasing doses of IMQ $(2.5-20 \mu \mathrm{g} / \mathrm{mL})$ simultaneously for $24 \mathrm{~h}$, both with and without IL-27 pretreatment. Doses of TL8 and IMQ were kept consistent when added alone with those used in Figure $2(500 \mathrm{ng} / \mathrm{mL}$ and $5 \mu \mathrm{g} /$ $\mathrm{mL}$, respectively).

Relative to untreated controls, treatment with IMQ alone did not significantly affect production of cytokines, but enhanced expression of IL-8 and RANTES in THP-1 cells (Fig. 3a, c). IL-27 pretreatment slightly enhanced IL-6 and IL- 8 production in IMQ-treated THP-1 cells (Fig. 3c, e); however, the resulting IL-6 production was significantly lower compared to IL-27 pretreated cells in the absence of IMQ. In PMA-THP-1 cells, IL-27 pretreatment enhanced IL- 8 and RANTES, but not TNF- $\alpha$ or IL6 , production in response to IMQ; however, the chemokine levels remained similar to IL-27 pretreated cells in the absence of IMQ (Fig. 3f, h). As expected, IL-27 pretreatment enhanced TNF- $\alpha$, IL-6, IL-8, and RANTES production from both cell types in response to stimulation with TL8 (500 ng/mL) alone (Fig. 3a-h). Interestingly, upon costimulation with TL8 and IMQ, TL8-induced TNF- $\alpha$ and IL- 6 production was significantly reduced in PMA-THP-1 cells in an IMQ dose-dependent manner (Fig. 3b, d; black bars). In THP-1 cells, levels of TL8-mediated TNF- $\alpha$ and IL- 6 expression remained low in the presence or absence of IMQ (Fig. 3a, c; black bars). In both cell types, pretreatment with IL-27 followed by stimulation with TL8 and increasing doses of IMQ (2.5$20 \mu \mathrm{g} / \mathrm{mL}$ ) resulted in significantly reduced TNF- $\alpha$ and IL-6 production (Fig. 3a-d; gray bars). When a dose of 20 $\mu \mathrm{g} / \mathrm{mL}$ of IMQ was used, TL8-induced TNF- $\alpha$ production was abrogated in both IL-27 pretreated THP-1 and PMATHP- 1 cells.
Fig. 2. Treatment with IL-27 results in elevated cytokine and chemokine production in response to TLR 8 or TLR7/8 agonists. THP1 (left column) and PMA-THP-1 (right column) cells were pretreated with IL-27 (50 ng/mL) for $16 \mathrm{~h}$, washed, then stimulated with IMQ $(5 \mu \mathrm{g} / \mathrm{mL})$, TL8 (500 ng/mL), R848 ( $5 \mu \mathrm{g} / \mathrm{mL})$, or CL075 $(2.5 \mu \mathrm{g} / \mathrm{mL})$ for $24 \mathrm{~h}$. Cell-free supernatants were collected for detection of TNF- $\alpha(\mathbf{a}, \mathbf{b})$, IL-6 $(\mathbf{c}, \mathbf{d}), \operatorname{IL}-8(\mathbf{e}, \mathbf{f})$, or RANTES $(\mathbf{g}, \mathbf{h})$ by ELISA. Data represent the mean and SEM of at least 5 replicate experiments. A paired, one-way ANOVA with multiple compari- sons and Bonferroni correction was used for statistical analyses between agonists and medium control as indicated by asterisks above bars or between pairs as indicated by asterisks above lines. ${ }^{*} p \leq 0.05 ;{ }^{* *} p \leq 0.01 ;{ }^{* * *} p \leq 0.001 ;{ }^{* * * *} p \leq 0.0001$. IMQ, imiquimod; R848, resiquimod; TLR7, Toll-like receptor 7; TLR8, Tolllike receptor 8; IL-27, interleukin-27; IL-6, interleukin-6; IL-8, interleukin-8; ELISA, enzyme-linked immunosorbent assay; PMA, phorbol 12-myristate 13-acetate.

(For figure see next page.) 


\section{THP-1 cells}
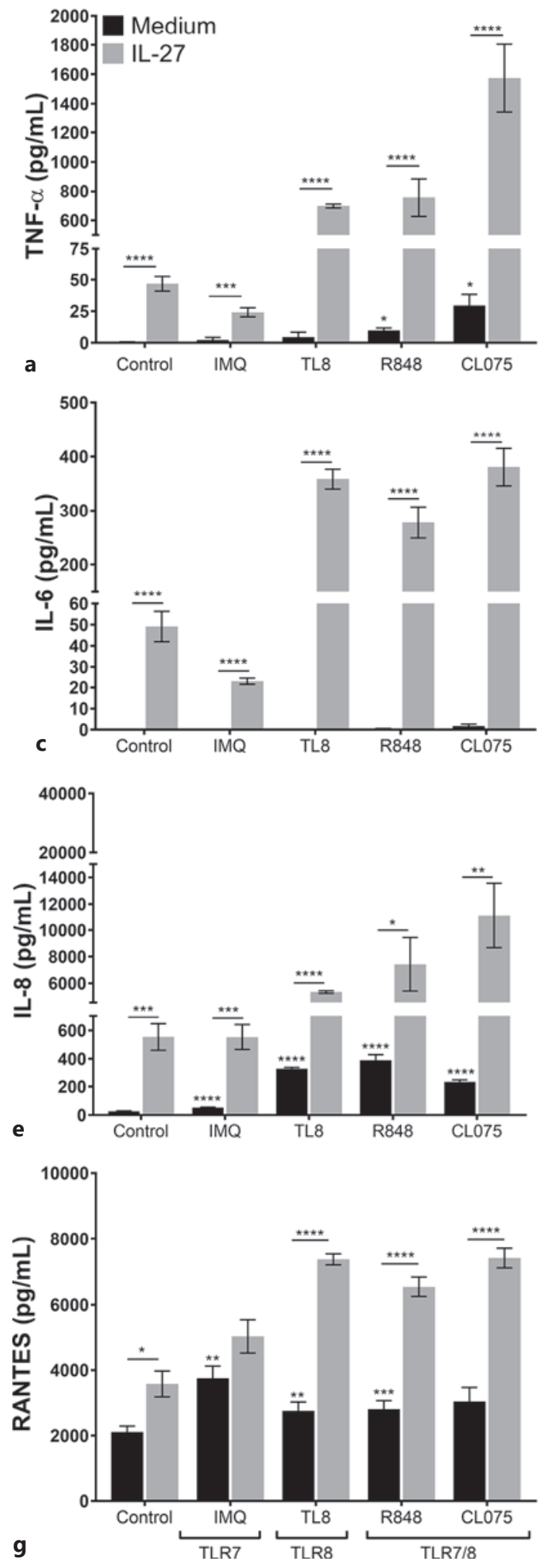

PMA THP-1 cells
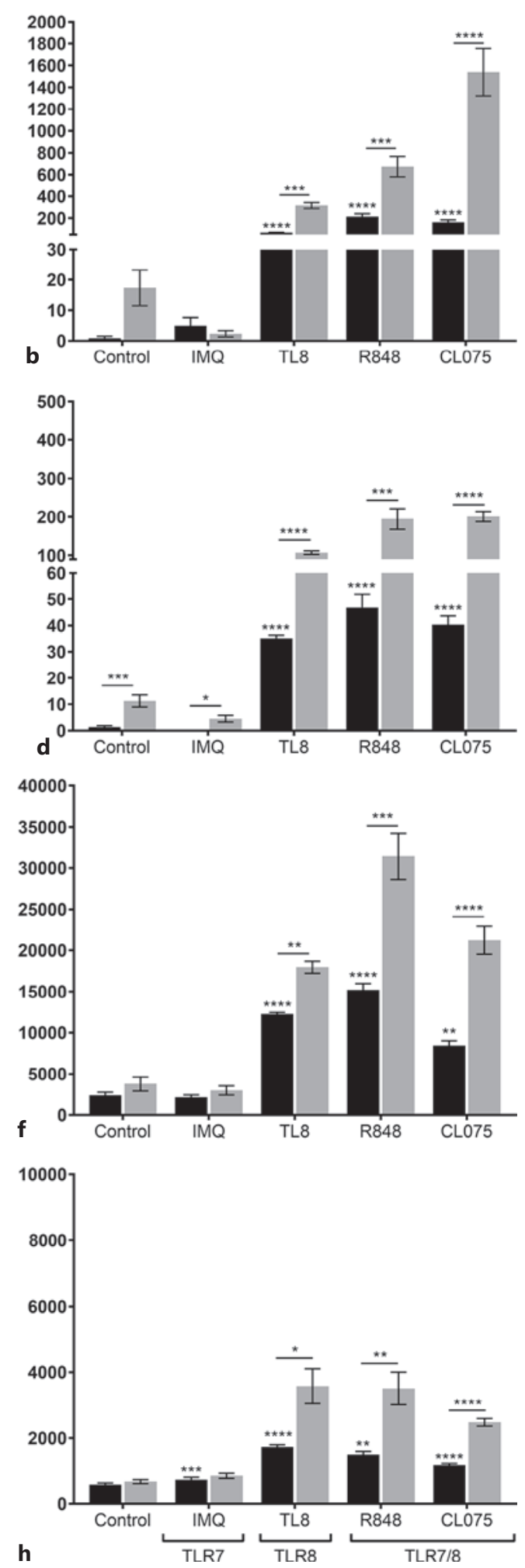
Interestingly, chemokine expression was differentially affected in THP-1 monocytes and PMA-THP-1 macrophages. In THP-1 cells, IMQ did not significantly inhibit expression of TL8-induced IL-8 or RANTES in either the presence or absence of IL-27 pretreatment (Fig. 3e, g); in fact, $20 \mu \mathrm{g} / \mathrm{mL}$ of IMQ significantly increased IL-8 production in THP-1 cells. However, in PMA-THP-1 cells, increasing doses of IMQ also reduced IL-8 and RANTES production, both in the presence and absence of IL-27 pretreatment in an IMQ dose-dependent manner similarly to the cytokines (Fig. 3f, g). Taken together, these results suggest that stimulation of TLR7 with IMQ differentially inhibits IL-27/TLR8-mediated production of proinflammatory mediators in monocytes and macrophages.

\section{IL-27 Differentially Modulates TLR7 and TLR8}

Expression in Human Monocytes and Macrophages

Previously, we showed that IL-27 upregulates cell surface expression of TLR 4 and TLR 5 on THP-1 monocytes and PMA-THP-1 macrophages [20-23, 25, 26]. Therefore, to determine if IL-27 has the same effect on TLR7 and TLR8, we analyzed mRNA levels and protein expression for these receptors. For mRNA analysis, qPCR was performed on THP-1 and PMA-THP-1 cells treated with IL-27 $(50 \mathrm{ng} / \mathrm{mL})$ for $4 \mathrm{~h}$. In comparison to untreated cells, IL-27 treatment induced a significant increase in TLR7 and TLR8 mRNA expression in both THP-1 cells and PMA-THP-1 cells (Fig. 4a). In THP-1 cells, TLR7 mRNA expression had an average 1.78-fold increase, and TLR8 mRNA had an average 2.06-fold increase in expression following IL-27 treatment. IL-27-treated PMATHP-1 cells had an average 1.45-fold increase in TLR7 mRNA expression and an average 1.64-fold increase in TLR8 mRNA expression. Of the 2 cell types, we observed a greater fold-change in mRNA expression in the THP-1 cells in comparison to PMA-THP-1 cells (Fig. 4a).

Next, to explore if these changes in mRNA correspond to protein expression, we treated both cell types with IL-

Fig. 3. Stimulation of monocytes and macrophages with TLR7 agonist IMQ results in reduced cytokine production. THP-1 (left) and PMA-THP-1 (right) cells were pretreated with IL-27 (50 ng/ $\mathrm{mL})$ for $16 \mathrm{~h}$, washed, then stimulated with either IMQ $(5 \mu \mathrm{g} / \mathrm{mL})$ alone, TL8-506 (TL8) (500 ng/mL) alone, or $500 \mathrm{ng} / \mathrm{mL}$ of TL8 with increasing doses of IMQ $(2.5-20 \mu \mathrm{g} / \mathrm{mL})$ for $24 \mathrm{~h}$. Cell-free supernatants were collected for detection of TNF-a (a, b), IL-6 (c, d), IL-8 (e, f), or RANTES $(\mathbf{g}, \mathbf{h})$ by ELISA. Data represent the mean and SEM of at least 3 replicate experiments. A paired, oneway ANOVA with multiple comparisons was used for statistical
27 for $16 \mathrm{~h}$ and analyzed intracellular TLR7 and TLR8 levels by flow cytometry. Interestingly, IL-27 enhanced intracellular expression of TLR7, but not TLR8 (Fig. 4b) and this trend was significant over several independent experiments (Fig. 4c). These data indicate the possibility that IL-27-mediated enhanced TLR7 expression together with IMQ signaling may differentially interfere with TLR8-mediated inflammatory cytokine and chemokine production in THP-1 cells and PMA-THP-1 cells.

\section{Discussion}

Findings from this study identified differences between TLR7 and TLR8 expression, signaling, and cytokine/chemokine induction in IL-27-treated THP-1 monocytes and PMA-THP-1 macrophages. Together, our data provide evidence for IL-27 as an important immunomodulatory cytokine that regulates TLR7 expression and dictates TLR8 responsiveness in human monocytes and macrophages. Furthermore, we demonstrate that the TLR7 agonist, imiquimod, antagonizes production of TLR8-mediated inflammatory cytokines and chemokines.

Overall, we observed that IL-27 pretreatment resulted in enhanced responsiveness to TLR8- or dual TLR7/8 agonists demonstrated by augmented cytokine and chemokine expression, with a distinctly lower cytokine/chemokine response to the TLR7 agonist, IMQ. Indeed, others have demonstrated that TLR8 stimulation of monocytes resulted in relatively high expression of proinflammatory cytokines including IL- 6 and TNF- $\alpha$, but TLR7 stimulation of monocytes resulted in relatively lower amounts of these cytokines $[32,33]$. Our work is also in agreement with Kalliolias and Ivashkiv [24], who indicated that IL27 treatment of primary human monocytes with a different TLR7/8 agonist, CL097, resulted in enhanced TNF- $\alpha$ and IL-6 expression. Furthermore, we showed a differential response between monocytic and macrophage-like

analyses between co-stimulated samples against TL8 alone (black bars) as indicated by asterisks above bars, in IL-27 pretreated costimulated samples versus IL-27 pretreated TL8-stimulated samples (gray bars) as indicated by asterisks above lines, or between pairs as indicated by asterisks above lines. ${ }^{*} p \leq 0.05$; ${ }^{* *} p \leq 0.01$; ${ }^{* * *} p \leq 0.001 ;{ }^{* * * *} p \leq 0.0001$. IMQ, imiquimod; R848, resiquimod; TLR7, Toll-like receptor 7; TLR8, Toll-like receptor 8; IL-27, interleukin-27; IL-6, interleukin-6; IL-8, interleukin-8; ELISA, enzymelinked immunosorbent assay; PMA, phorbol 12-myristate 13-acetate. 
THP-1 cells
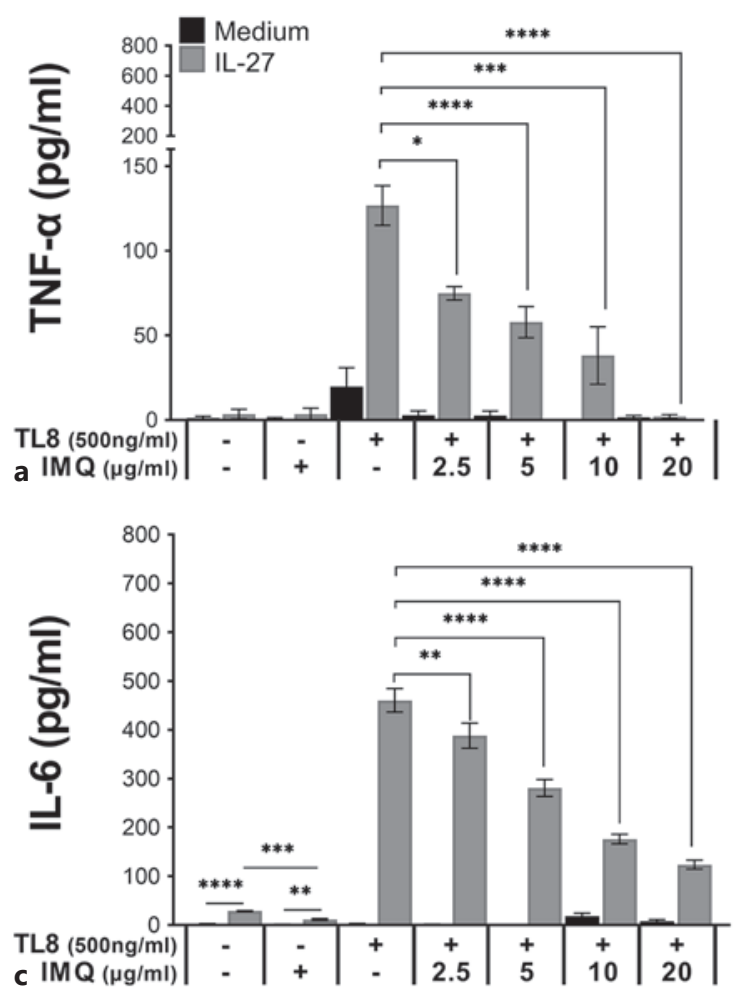

C IMQ $(\mu \mathrm{g} / \mathrm{mI})$
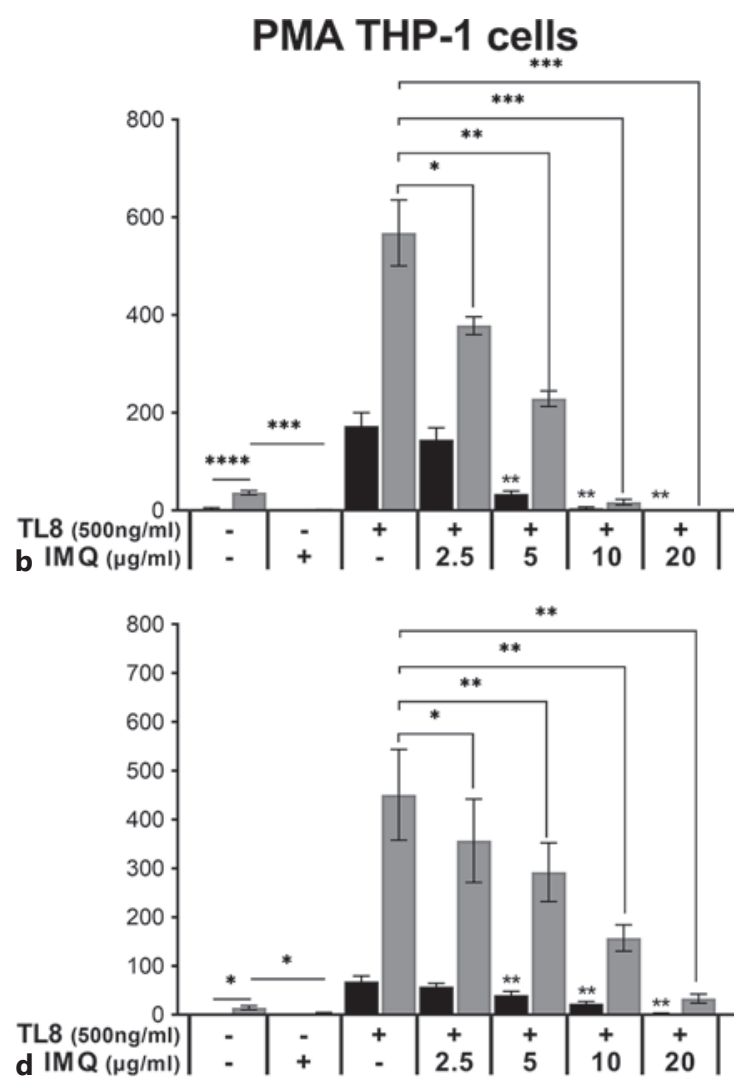
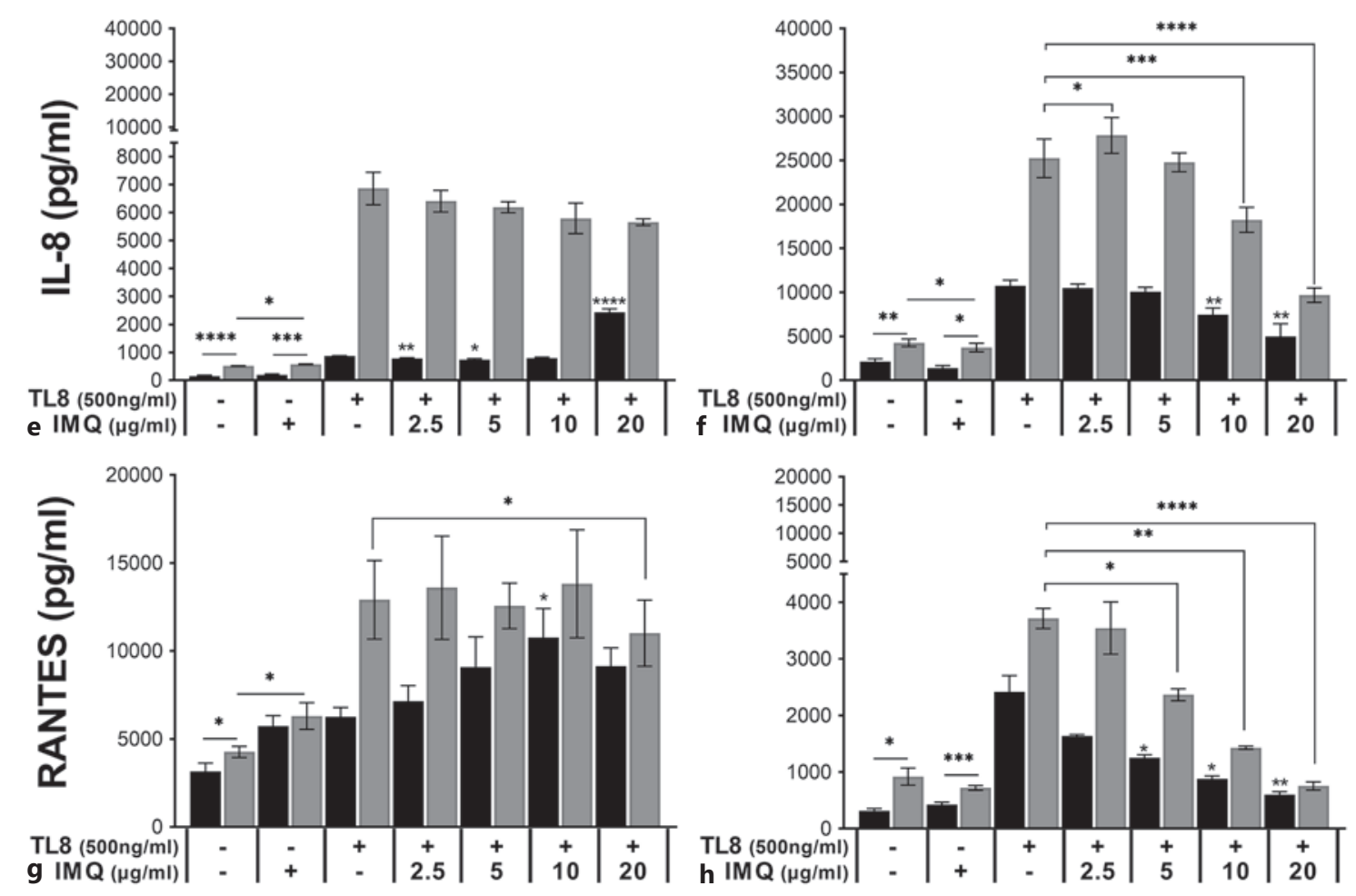


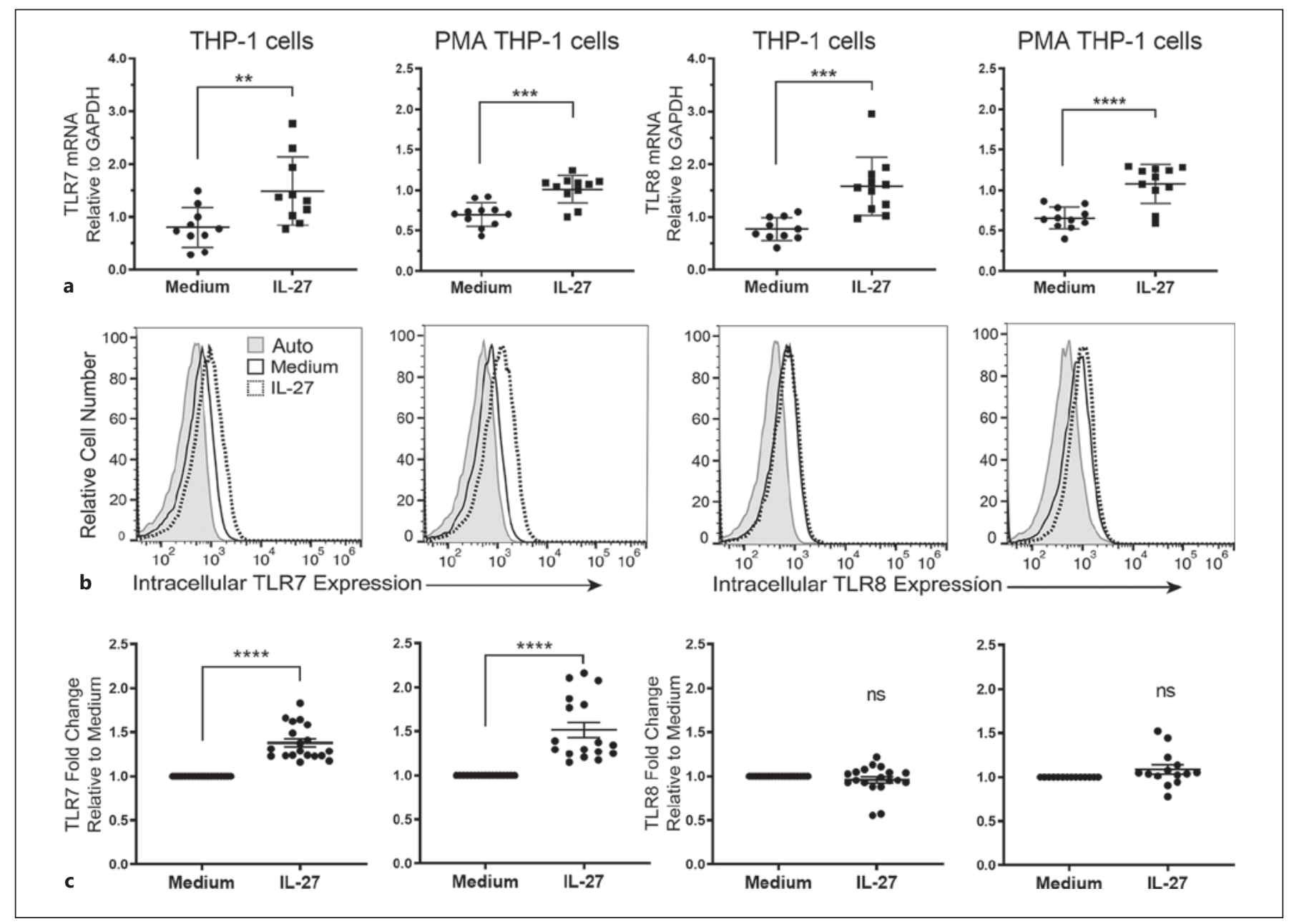

Fig. 4. IL-27 enhances both TLR7 and TLR8 mRNA levels, but differentially modulates protein expression. a THP-1 cells and PMATHP-1 cells were treated with or without IL-27 (50 ng/mL) for $4 \mathrm{~h}$ and qPCR was performed to examine changes in TLR7 (left) or TLR8 (right) mRNA expression. b THP-1 and PMA-THP-1 cells were stimulated with IL-27 (50 ng/mL) for $16 \mathrm{~h}$ then fixed, permeabilized, then stained for intracellular TLR7 or TLR8 expression in comparison to medium cultured cells. Unstained cells (auto; shaded histogram) are included for negative controls. Histograms displayed are representative of 5 independent experi-

cells when concurrently stimulated with IMQ and TL8, where we observed an inhibition of TLR8-induced proinflammatory cytokine expression in both cell types when pretreated with IL-27 and an inhibition of the chemokines only in PMA-THP-1 cells.

Our data using a time point of $16 \mathrm{~h}$ of IL-27 treatment suggest that after IL-27 is induced in response to a virus infection, an inflammatory response from uninfected bystander monocytes and macrophages is initiated. Indeed, IL-27 is detected in the serum of IAV-infected patients ments with at least 14 replicates total. c Fold change was calculated between IL-27-treated samples and medium controls. Each point represents a replicate value within an independent experiment. Data were analyzed using students $t$ tests for statistical analyses between pairs as indicated. ns, not significant; ${ }^{*} p \leq 0.05 ;{ }^{*} p \leq 0.01$; ${ }^{* * *} p \leq 0.001 ;{ }^{* * * *} p \leq 0.0001$. TLR7, Toll-like receptor 7; TLR8, Toll-like receptor 8; IL-27, interleukin-27; qPCR, quantitative realtime polymerase chain reaction; PMA, phorbol 12-myristate 13-acetate.

$[19,34]$ and thus could influence monocytes in circulation in addition to tissue resident macrophages, such as alveolar macrophages which would be localized to the area of IAV infection. Furthermore, IL-27-primed cells exhibit upregulated TLR8 responsiveness, characterized by enhanced proinflammatory cytokine and chemokine expression. Upregulation of cytokines (IL-6 and TNF- $\alpha$ ) and chemokines (RANTES, IL-8) may serve to recruit and activate immune cells at the site of virus infection. It is further interesting to note that type I IFN expression 
was not detectable in our system. As many viruses inhibit the antiviral response led by type I IFNs, the enhancement of TLR7/8 responsiveness by IL-27 may serve to prime the innate immune response to respond to virus infection in the absence of type I IFN induction. Indeed, other studies have shown an antiviral effect of IL-27 in HIV infection of macrophages, CD4 T cells, and dendritic cells that can occur independently of type I IFN expression [35]. Moreover, dendritic cells are the prevailing cell type responsible for type I IFN production in response to virus infection [36] and future study of the role of IL-27 on TLR7 and TLR8 responsiveness during virus infection in this cell type is warranted.

Differences in the response to stimulation with TLR7 versus TLR8 and TLR7/8 agonists could be explained by differences in signal transduction activity. Upon ligand binding, TLR7 and TLR8 rely on a MyD88-dependent signaling cascade involving IL-1 receptor-associated kinase (IRAK) family members, tumor necrosis factor receptor-associated factor 6 (TRAF6), and MAPK in order to activate NF- $\kappa \mathrm{B} / \mathrm{AP}-1$ transcription factors to promote proinflammatory cytokine production [11]. IL-27-pretreated THP-1 cells displayed high phosphorylation of p38 and ERK1/2, and NF- $\mathrm{KB} / \mathrm{AP}-1$ activity in the absence of TLR agonists, indicating that IL-27-treated cells may be primed for higher signaling activity in comparison to untreated cells. Upon addition of TL8, R848, or CL075 to IL-27-primed cells, the enhanced NF- $\kappa \mathrm{B} / \mathrm{AP}-1$ activity may be partially responsible for the induction of cytokine and chemokine expression as TNF- $\alpha$, IL-6, IL-8, and RANTES, which occur downstream of NF- $\kappa$ B and AP-1 activation [31]. In support of this study using $5 \mu \mathrm{g} / \mathrm{mL}$ of R848, others demonstrated that in cells treated with R848 at doses ranging from 1 to $10 \mu \mathrm{g} / \mathrm{mL}$, TLR8 more effectively induced NF- $\kappa \mathrm{B}$ activity compared to TLR7 [37]. Furthermore, others have shown that in primary human monocytes, TLR7 preferentially signals through the MAPK cascade to induce AP-1 induction where TLR8 signals via NF- $\kappa \mathrm{B}[8]$. Taken together, these studies suggest an explanation for the elevated cytokine and chemokine expression observed in response to R848 and potentially TL8.

Compared to THP-1 cells, we observed relatively higher signaling activity in PMA-THP-1 macrophages in every condition. PMA is a protein kinase $\mathrm{C}(\mathrm{PKC})$ activator that results in the activation of MAPK including ERK1/2 and subsequent NF- $\kappa \mathrm{B} / \mathrm{AP}-1$ activity [38]. While the activation of TLR signaling by agonists resulted in high proinflammatory cytokine production in PMA-THP-1 cells, significant differences in NF- $\mathrm{kB} / \mathrm{AP}-1$ activity following

IL-27 Amplifies TLR7 Expression and TLR8 Function
IL-27 pretreatment were not detected. It is possible that PMA will activate other intracellular signaling cascades in these cells. However, induction of proinflammatory cytokines by TLRs in macrophages involves other transcription factors in addition to NF- $\kappa$ B and AP-1, such as NFAT5 $[39,40]$. This may explain the absence of measurable NF- $\kappa \mathrm{B} / \mathrm{AP}-1$ activity in PMA-THP-1 cells in response to TL8, as well as the lack of difference between R848 or CL075 alone and IL-27 plus R848 or CL075, while inducing significant production of proinflammatory cytokines and chemokines under these conditions.

We reasoned that differences in TLR7 or TLR8 expression in response to IL-27 treatment could also contribute to the differential cytokine and chemokine induction in THP-1 and PMA THP-1 cells with respect to IMQ and TL8. We observed that IL-27 enhanced TLR7 mRNA and protein expression, and although we observed enhanced TLR8 mRNA, this did not correlate with TLR8 protein expression. Thus, in cells treated with either IMQ or TL8 alone, changes in receptor expression may not account for the observed differences in cytokine responses to IMQ and TL8 with or without IL-27 pretreatment. Cross-talk between TLRs has been documented between several TLR pairs in monocyte-derived dendritic cells, monocytes, and macrophages [41-43]. A previous study by Wang et al. [41] showed that the presence of TLR8 selectively inhibited both TLR7 and TLR9 through direct or indirect interactions. Furthermore, although PMATHP-1 cells expressed TLR7, they were nonresponsive to the TLR7 specific agonist 3M-001, which the authors suggested may be due to inhibition by the expression of TLR 8 [41]. These findings align with our results, where neither THP-1 nor PMA-THP-1 cells displayed high levels of proinflammatory cytokine production in response to IMQ alone, but both cell types were highly responsive to TLR8 stimulation, and even more so in IL-27 pretreated cells.

Interestingly, in THP-1 cells, chemokine expression was not inhibited in cells costimulated with IMQ and TL8, regardless of prior IL-27 stimulation; this indicates the likelihood that chemokine (IL-8 and RANTES) production is differentially regulated from cytokine (TNF- $\alpha$ and IL-6) production under these conditions. The potential mechanism underlying the inhibition of TL8-induced cytokine/chemokine expression by IMQ could be a result of the IL-27-mediated upregulation of TLR7 expression. Increased TLR7 expression as a result of IL-27 priming may induce negative regulators of TLR signaling in response IMQ [44, 45]. Negative regulators activated by IMQ stimulation that are expressed by THP-1 cells may 
impede TL8-TLR8 downstream signaling responsible for the production of TNF- $\alpha$ and IL-6, but not for IL- 8 or RANTES. In PMA-THP- 1 cells, different negative regulators or signaling pathways may be induced by IMQ that block the expression of both cytokines and chemokines. Furthermore, others have determined that simultaneous ligation of surface TLRs, TLR4 or TLR5, along with TLR8 ligation resulted in suppressed TLR8-IRF5 signaling in human monocytes [46]. A similar mechanism may be occurring where ligation of TLR7 suppresses TLR8 signaling when IMQ is added to THP-1 and PMA-THP-1 cells in addition to TL8. As others have observed TLR9 functioning to prevent overactivation of TLR7 [41, 47], in our model, inhibition by increased ligand binding to TLR7 may serve as a protective mechanism to avoid overproduction of proinflammatory cytokines by TLR8 ligation that could be detrimental to the host. This is particularly relevant to ssRNA virus infection, as viruses, such as influenza virus, dengue, and coronaviruses, can elicit deadly cytokine storms $[48,49]$. A greater understanding of the contributions of TLR7 and TLR8 to cytokine storm induction may reveal new targets for treatment.

Further investigation on how IL-27 contributes to distinct TLR7- and TLR8-mediated signaling is needed to determine how cytokine and chemokine expression is regulated in monocytes and macrophages. TLR7 and TLR8 are crucial for the detection of ssRNA virus infection by innate immune cells and are largely responsible for inducing antiviral responses such as proinflammatory cytokine secretion and type I IFN production [50, 51]. It is interesting to note that IL-27-mediated signaling is protective during infection with ssRNA viruses such as Zika, LCMV [52], and IAV [19]. Thus, it is possible that virus-induced IL-27 may influence the antiviral responses triggered by TLR7 or TLR8 ligation. Moreover, it is appreciated that infection of myeloid cells with live virus may also differentially modulate signaling from TLR7 and TLR8. Indeed, infection of monocytes with a panel of ssRNA viruses demonstrated the importance of differential TLR7 and TLR8 signaling as it relates to cytokine induction in inducing virusspecific immune responses [8]. Stimulation with TLR7 and TLR8 ligands can also trigger IL-27 expression in other inflammatory models; for example, in a murine experimental asthma model, IL-27 was found to be essential for R848-induced therapeutic effects [53]. Indeed, a role for IL-27 is demonstrated in psoriasis, where the TLR7 signaling axis drives IL-27 expression, which exacerbates inflammation and disease severity [54]. This indicates that our data are relevant to consider in models of viral infection and autoimmune disease. Altogether, our results identify a novel role of IL-27 on affecting TLR8 responsiveness in human monocytes and macrophages. Moreover, this study highlights a prominent role for TLR8 in responding to ssRNA viruses in terms of promoting proinflammatory responses from myeloid cells with TLR7 ligation acting as a potential negative regulator.

\section{Acknowledgments}

We would like to thank Sean Wells and Claude Lachance (BioRad) for expertise with the CFX96 Touch ${ }^{\mathrm{TM}}$ Real-Time PCR Detection System and accompanying software to acquire data for this publication.

\section{Statement of Ethics}

The study protocols were reviewed and approved by the Queen's University Biohazard Committee, approval number: 6026082. No ethics approval was required for this work as it was performed in vitro using a cell line and no primary human samples were used.

\section{Conflict of Interest Statement}

The authors declare no competing financial interests.

\section{Funding Sources}

This work is supported by grants from the Natural Sciences and Engineering Research Council of Canada (grant: 342168). N.O. was supported by the NSERC Alexander Graham Bell Canadian Graduate Scholarship-Master's. O.K. was supported by an Ontario Graduate Scholarship and NSERC Alexander Graham Bell Canadian Graduate Scholarship-Doctoral award. C.P. was supported by an Ontario Graduate Scholarship, Dr. Robert John Wilson Graduate Fellowship, and NSERC-Postgraduate Scholarship-Doctoral award.

\section{Author Contributions}

N.O. designed the study and performed experiments. O.K. contributed to data presented in Figure 3. C.P. performed preliminary experiments. N.O., O.K., C.P., and S.B. contributed to the conceptualization of the project and writing of the manuscript. K.G. oversaw the conception of the study, experimental plans, and writing of the manuscript. 


\section{References}

1 Blasius AL, Beutler B. Intracellular toll-like receptors. Immunity. 2010;32(3):305-15.

2 Diebold SS, Kaisho T, Hemmi H, Akira S, Reis e Sousa C. Innate antiviral responses by means of TLR7-mediated recognition of single-stranded RNA. Science. 2004;303(5663): 1529-31.

3 He X, Jia H, Jing Z, Liu D. Recognition of pathogen-associated nucleic acids by endosomal nucleic acid-sensing toll-like receptors. Acta Biochim Biophys Sin. 2013;45(4):241-58.

4 Moreno-Eutimio MA, López-Macías C, Pastelin-Palacios R. Bioinformatic analysis and identification of single-stranded RNA sequences recognized by TLR7/8 in the SARSCoV-2, SARS-CoV, and MERS-CoV genomes. Microbes Infect. 2020 May-Jun;22(45):226-9.

5 Qian C, Cao X. Regulation of Toll-like receptor signaling pathways in innate immune responses. Ann N Y Acad Sci. 2013;1283:67-74.

6 Lester SN, Li K. Toll-like receptors in antiviral innate immunity. J Mol Biol. 2014;426(6) 1246-64.

7 Barton GM, Medzhitov R. Toll-like receptor signaling pathways. Science. 2003;300(5625): 1524-5.

8 de Marcken M, Dhaliwal K, Danielsen AC, Gautron AS, Dominguez-Villar M. TLR7 and TLR8 activate distinct pathways in monocytes during RNA virus infection. Sci Signal. 2019; 12(605):eaaw1347.

9 Alexopoulou L, Holt AC, Medzhitov R, Flavell RA. Recognition of double-stranded RNA and activation of NF-kappaB by Toll-like receptor 3. Nature. 2001;413(6857):732-8.

10 Lund JM, Alexopoulou L, Sato A, Karow M, Adams NC, Gale NW, et al. Recognition of single-stranded RNA viruses by Toll-like receptor 7. Proc Natl Acad Sci U S A. 2004; 101(15):5598-603.

11 Kawai T, Akira S. Toll-like receptor and RIGI-like receptor signaling. Ann N Y Acad Sci. 2008;1143:1-20.

12 Pflanz S, Timans JC, Cheung J, Rosales R, Kanzler H, Gilbert J, et al. IL-27, a heterodimeric cytokine composed of EBI3 and p28 protein, induces proliferation of naive CD4 $(+)$ T cells. Immunity. 2002;16(6):779-90.

13 Aparicio-Siegmund S, Garbers C. The biology of interleukin-27 reveals unique pro- and antiinflammatory functions in immunity. Cytokine Growth Factor Rev. 2015;26(5):579-86.

14 Dai L, Lidie KB, Chen Q, Adelsberger JW, Zheng X, Huang D, et al. IL-27 inhibits HIV1 infection in human macrophages by downregulating host factor SPTBN1 during monocyte to macrophage differentiation. J Exp Med. 2013;210(3):517-34.

15 Feng XM, Liu N, Yang SG, Hu LY, Chen XL, Fang $\mathrm{ZH}$, et al. Regulation of the class II and class I MHC pathways in human THP-1 monocytic cells by interleukin-27. Biochem Biophys Res Commun. 2008;367(3):553.
16 Frank AC, Zhang X, Katsounas A, Bharucha JP, Kottilil S, Imamichi T. Interleukin-27, an anti-HIV-1 cytokine, inhibits replication of hepatitis $\mathrm{C}$ virus. J Interferon Cytokine Res. 2010;30(6):427-31.

17 Imamichi T, Yang J, Huang DW, Brann TW, Fullmer BA, Adelsberger JW, et al. IL-27, a novel anti-HIV cytokine, activates multiple interferon-inducible genes in macrophages. AIDS. 2008;22(1):39-45.

18 Jung JY, Roberts LL, Robinson CM. The presence of interleukin-27 during monocyte-derived dendritic cell differentiation promotes improved antigen processing and stimulation of T cells. Immunology. 2015;144(4): 649-60.

19 Liu L, Cao Z, Chen J, Li R, Cao Y, Zhu C, et al. Influenza A virus induces interleukin-27 through cyclooxygenase- 2 and protein kinase A signaling. J Biol Chem. 2012;287(15): 11899-910.

20 Guzzo C, Ayer A, Basta S, Banfield BW, Gee K. IL-27 enhances LPS-induced proinflammatory cytokine production via upregulation of TLR4 expression and signaling in human monocytes. J Immunol. 2012;188(2): 864-73.

21 Petes C, Mintsopoulos V, Finnen RL, Banfield BW, Gee K. The effects of CD14 and IL-27 on induction of endotoxin tolerance in human monocytes and macrophages. J Biol Chem. 2018;293(45):17631-45.

22 Petes C, Odoardi N, Plater SM, Martin NL, Gee K. IL-27 amplifies cytokine responses to Gram-negative bacterial products and Salmonella typhimurium infection. Sci Rep. 2018; 8(1):13704.

23 Petes C, Wynick C, Guzzo C, Mehta D, Logan S, Banfield BW, et al. IL-27 enhances LPS-induced IL-1 $\beta$ in human monocytes and murine macrophages. J Leukoc Biol. 2017;102(1): 83-94.

24 Kalliolias GD, Ivashkiv LB. IL-27 activates human monocytes via STAT1 and suppresses IL-10 production but the inflammatory functions of IL-27 are abrogated by TLRs and p38. J Immunol. 2008;180(9):6325-33.

25 Petes C, Mariani MK, Yang Y, Grandvaux N, Gee K. Interleukin (IL)-6 inhibits IL-27- and IL-30-mediated inflammatory responses in human monocytes. Front Immunol. 2018 Feb 15;9:256.

26 Guzzo C, Che Mat NF, Gee K. Interleukin-27 induces a STAT1/3- and NF-kappaB-dependent proinflammatory cytokine profile in human monocytes. J Biol Chem. 2010;285(32): 24404-11.

27 Shimizu M, Ogura K, Mizoguchi I, Chiba Y, Higuchi K, Ohtsuka H, et al. IL-27 promotes nitric oxide production induced by LPS through STAT1, NF- $\mathrm{B}$ and MAPKs. Immunobiology. 2013;218(4):628-34.
28 Greenwell-Wild T, Vázquez N, Jin W, Rangel Z, Munson PJ, Wahl SM. Interleukin-27 inhibition of HIV-1 involves an intermediate induction of type I interferon. Blood. 2009; 114(9):1864-74.

29 Daigneault M, Preston JA, Marriott HM, Whyte MK, Dockrell DH. The identification of markers of macrophage differentiation in PMA-stimulated THP-1 cells and monocytederived macrophages. PLoS One. 2010;5(1): e8668.

$30 \mathrm{Na} \mathrm{BH}$, Hoang TX, Kim JY. Hsp90 inhibition reduces TLR5 surface expression and NF- $\kappa \mathrm{B}$ activation in human myeloid leukemia THP1 cells. Biomed Res Int. 2018;2018:4319369.

31 Mogensen TH, Paludan SR. Molecular pathways in virus-induced cytokine production. Microbiol Mol Biol Rev. 2001;65(1):131-50.

32 Bender AT, Tzvetkov E, Pereira A, Wu Y, Kasar S, Przetak MM, et al. TLR7 and TLR8 differentially activate the IRF and NF- $\kappa \mathrm{B}$ pathways in specific cell types to promote inflammation. Immunohorizons. 2020;4(2): 93-107.

33 Gorden KB, Gorski KS, Gibson SJ, Kedl RM, Kieper WC, Qiu X, et al. Synthetic TLR agonists reveal functional differences between human TLR7 and TLR8. J Immunol. 2005; 174(3):1259-68.

34 Liu L, Li R, Pan Y, Chen J, Li Y, Wu J, et al. High-throughput screen of protein expression levels induced by cyclooxygenase- 2 during influenza a virus infection. Clin Chim Acta. 2011;412(11-12):1081-5.

35 Chen Q, Swaminathan S, Yang D, Dai L, Sui $\mathrm{H}$, Yang J, et al. Interleukin-27 is a potent inhibitor of cis HIV-1 replication in monocytederived dendritic cells via a type I interferonindependent pathway. PLoS One. 2013;8(3): e59194.

36 Fitzgerald-Bocarsly P, Feng D. The role of type I interferon production by dendritic cells in host defense. Biochimie. 2007;89(6-7):843-55.

37 Jurk M, Heil F, Vollmer J, Schetter C, Krieg AM, Wagner $\mathrm{H}$, et al. Human TLR7 or TLR8 independently confer responsiveness to the antiviral compound R-848. Nat Immunol. 2002;3(6):499.

38 Traore K, Trush MA, George M Jr., Spannhake EW, Anderson W, Asseffa A. Signal transduction of phorbol 12-myristate 13-acetate (PMA)-induced growth inhibition of human monocytic leukemia THP-1 cells is reactive oxygen dependent. Leuk Res. 2005;29(8): 863-79.

39 Buxadé M, Lunazzi G, Minguillón J, Iborra S, Berga-Bolaños R, del Val M, et al. Gene expression induced by Toll-like receptors in macrophages requires the transcription factor NFAT5. J Exp Med. 2012;209(2):379-93.

40 Ranjbar S, Jasenosky LD, Chow N, Goldfeld AE. Regulation of Mycobacterium tuberculosis-dependent HIV-1 transcription reveals a new role for NFAT5 in the toll-like receptor pathway. PLoS Pathog. 2012;8(4):e1002620. 
41 Wang J, Shao Y, Bennett TA, Shankar RA, Wightman PD, Reddy LG. The functional effects of physical interactions among Toll-like receptors 7, 8, and 9. J Biol Chem. 2006; 281(49):37427-34.

42 Tan RS, Ho B, Leung BP, Ding JL. TLR crosstalk confers specificity to innate immunity. Int Rev Immunol. 2014;33(6):443-53.

43 Bösl K, Giambelluca M, Haug M, Bugge M, Espevik T, Kandasamy RK, et al. Coactivation of TLR2 and TLR8 in primary human monocytes triggers a distinct inflammatory signaling response. Front Physiol. 2018;9:618.

44 Cao X. Self-regulation and cross-regulation of pattern-recognition receptor signalling in health and disease. Nat Rev Immunol. 2016; 16(1):35-50.

45 Kondo T, Kawai T, Akira S. Dissecting negative regulation of Toll-like receptor signaling. Trends Immunol. 2012;33(9):449-58.
46 Moen SH, Ehrnström B, Kojen JF, Yurchenko M, Beckwith KS, Afset JE, et al. Human tolllike receptor 8 (TLR8) is an important sensor of pyogenic bacteria, and is attenuated by cell surface TLR signaling. Front Immunol. 2019; 10(1209):1209.

47 Fukui R, Saitoh S, Matsumoto F, Kozuka-Hata $\mathrm{H}$, Oyama M, Tabeta K, et al. Unc93B1 biases Toll-like receptor responses to nucleic acid in dendritic cells toward DNA- but against RNA-sensing. J Exp Med. 2009; 206(6):1339-50.

48 Tisoncik JR, Korth MJ, Simmons CP, Farrar J, Martin TR, Katze MG. Into the eye of the cytokine storm. Microbiol Mol Biol Rev. 2012;76(1):16-32.

49 Tang Y, Liu J, Zhang D, Xu Z, Ji J, Wen C. Cytokine storm in COVID-19: the current evidence and treatment strategies. Front Immunol. 2020;11:1708.

50 Chen N, Xia P, Li S, Zhang T, Wang TT, Zhu J. RNA sensors of the innate immune system and their detection of pathogens. IUBMB Life. 2017;69(5):297-304.
51 Uematsu S, Akira S. Toll-like receptors and type I interferons. J Biol Chem. 2007;282(21): 15319-23.

52 Harker JA, Wong KA, Dallari S, Bao P, Dolgoter A, Jo Y, et al. Interleukin-27R signaling mediates early viral containment and impacts innate and adaptive immunity after chronic lymphocytic choriomeningitis virus infection. J Virol. 2018 May 29;92(12):e02196-17.

53 Jirmo AC, Daluege K, Happle C, Albrecht M, Dittrich AM, Busse M, et al. IL-27 is essential for suppression of experimental allergic asthma by the TLR7/8 agonist R848 (resiquimod). J Immunol. 2016;197(11):4219-27.

54 Shibata S, Tada Y, Asano Y, Yanaba K, Sugaya M, Kadono T, et al. IL-27 activates Th1-mediated responses in imiquimod-induced psoriasis-like skin lesions. J Invest Dermatol. 2013; 133(2):479-88. 